\title{
Nanocrystal technology, drug delivery and clinical applications
}

\author{
Jens-Uwe A H Junghanns \\ Rainer H Müller \\ Department of Pharmaceutical \\ Technology, Biotechnology and \\ Quality Management, Free University \\ of Berlin, Berlin, Germany
}

\begin{abstract}
Nanotechnology will affect our lives tremendously over the next decade in very different fields, including medicine and pharmacy. Transfer of materials into the nanodimension changes their physical properties which were used in pharmaceutics to develop a new innovative formulation principle for poorly soluble drugs: the drug nanocrystals. The drug nanocrystals do not belong to the future; the first products are already on the market. The industrially relevant production technologies, pearl milling and high pressure homogenization, are reviewed. The physics behind the drug nanocrystals and changes of their physical properties are discussed. The marketed products are presented and the special physical effects of nanocrystals explained which are utilized in each market product. Examples of products in the development pipelines (clinical phases) are presented and the benefits for in vivo administration of drug nanocrystals are summarized in an overview.
\end{abstract}

Keywords: drug nanocrystals, pearl milling, high pressure homogenization, nanocrystal, DissoCubes, Nanopure, bioavailability enhancement, saturation solubility, dissolution velocity

\section{Introduction}

Today nanotechnology is encountered all around our daily lives. Whether it be in the production of computer chips (where the need to fit more integrated circuits per square millimeter is evident to produce chips with more computing power [Kanellos 2005]), the increasing field of biotechnology (where new tools to easily interact with proteins in ever smaller sizes are needed [Merkle 1999]) or simply cosmetic research and products (where nanonized agents can provide a whole range of benefits [Müller et al 2006]). In all these fields the need for ever decreased size is common. The nanonization of products, whether for medical use (eg, mini robots to clean arteries [Kazimierski 2005]), the food industry (eg, nanoencapsulated vitamins for so called functional food [Velikov 2006]) or the application of drugs for pharmaceutical use, is an important factor both on the economical, as well as on the medical or pharmaceutical side. From the first write-through paper (where microencapsulated ink was used as a thin layer on the back of the top-sheet and the impact of the typewriter broke the capsules to release the ink to the lower sheet [Cinzia De Vita 2004]), nanotechnology has helped to achieve progress all around us. This article will focus on nanosized crystals in medical application. In drug delivery and clinical applications the technology to nanonize (ie, to reduce in size to below $1000 \mathrm{~nm}$ ) is one of the key factors for modern drug therapy, now and in the years to come.

Over the last ten years, the number of poorly soluble drugs has steadily increased. Estimates state that $40 \%$ of the drugs in the pipelines have solubility problems (Speiser 1998). Progress in high throughput screening methods leads to an even greater amount of newly discovered drugs that have poor water solubility. Literature states that about $60 \%$ of all drugs coming directly from synthesis are nowadays poorly soluble (Merisko-Liversidge 2002). Poor solubility in water correlates with poor 
bioavailability. If there is no way to improve drug solubility it will not be able to be absorbed from the gastrointestinal tract into the bloodstream and reach the site of action.

There are many ways to solubilize certain poorly soluble drugs. But these methods are limited to drugs with certain properties in regard to their chemistry (eg, solubility in certain organic media) or for example to their molecular size or conformation (eg, molecules to be incorporated into the cyclodextrin [CD] ring structure [Grau 2000]). Apart from that, the usage of surfactants or cosolvents is also possible, but sometimes leads to increased side effects (eg, Cremophor EL (BASF, Ludwigshafen, Germany) increases the toxicity of Taxol and HP-ß-cyclodextrin is the cause of nephrotoxicity of itraconazole in Sporanox ${ }^{\circledR}$ [Willems et al 2001]) and other disadvantages (eg, organic solvent residues). The micronization of drug powders to sizes between 1 and $10 \mu \mathrm{m}$ in order to increase the surface area, and thus the dissolution velocity, is not sufficient to overcome bioavailability problems of many very poorly soluble drugs of the biopharmaceutical specification class II. A consequent step was to move from micronization to nanonization. Since the beginning of the 90s, Elan Nanosystems (San Francisco, CA, USA) propagated the use of nanocrystals instead of microcrystals for oral bioavailability enhancement, but also to use nanocrystals suspended in water (nanosuspensions) for intravenous or pulmonary drug delivery.

\section{Definition}

Drug nanocrystals are crystals with a size in the nanometer range, which means they are nanoparticles with a crystalline character. There are discussions about the definition of a nanoparticle, which means the size of a particle to be classified as a nanoparticle, depending on the discipline, eg, in colloid chemistry particles are only considered as nanoparticles when they are in size below $100 \mathrm{~nm}$ or even below $20 \mathrm{~nm}$. Based on the size unit, in the pharmaceutical area nanoparticles should be defined as having a size between a few nanometers and $1000 \mathrm{~nm}(=1 \mu \mathrm{m})$; microparticles therefore possess a size of $1-1000 \mu \mathrm{m}$.

A further characteristic is that drug nanocrystals are composed of $100 \%$ drug; there is no carrier material as in polymeric nanoparticles. Dispersion of drug nanocrystals in liquid media leads to so called "nanosuspensions" (in contrast to "microsuspensions" or "macrosuspensions"). In general the dispersed particles need to be stabilized, such as by surfactants or polymeric stabilizers. Dispersion media can be water, aqueous solutions or nonaqueous media (eg, liquid polyethylene glycol [PEG], oils).
Depending on the production technology, processing of drug microcrystals to drug nanoparticles can lead to an either crystalline or to an amorphous product, especially when applying precipitation. In the strictest sense, such an amorphous drug nanoparticle should not be called nanocrystal. However, often one refers to "nanocrystals in the amorphous state".

\section{Properties of nanocrystals}

The main reasons for the increased dissolution velocity and thus increased bioavailability are:

\section{Increase of dissolution velocity by surface area enlargement}

The size reduction leads to an increased surface area and thus according to the Noyes-Whitney equation (Noyes and Whitney 1897) to an increased dissolution velocity. Therefore micronization is a suitable way to successfully enhance the bioavailability of drugs where the dissolution velocity is the rate limiting step. By moving from micronization further down to nanonization, the particle surface is further increased and thus the dissolution velocity increases too. In most cases, a low dissolution velocity is correlated with low saturation solubility (Figure 1).

\section{Increase in saturation solubility}

The general textbook statement is that the saturation solubility $\mathrm{c}_{\mathrm{s}}$ is a constant depending on the compound, the dissolution medium and the temperature. This is valid for powders of daily life with a size in the micrometer range or above. However, below a critical size of $1-2 \mu \mathrm{m}$, the saturation solubility is also a function of the particle size. It increases with decreasing particle size below $1000 \mathrm{~nm}$. Therefore, drug nanocrystals possess increased saturation solubility. This has two advantages:

1. According to Noyes and Whitney (1897), the dissolution velocity is further enhanced because $\mathrm{dc} / \mathrm{dt}$ is proportional to the concentration gradient $\left(\mathrm{c}_{\mathrm{s}}-\mathrm{c}_{\mathrm{x}}\right) / \mathrm{h}\left(\mathrm{c}_{\mathrm{s}}\right.$ - saturation solubility, $\mathrm{c}_{\mathrm{x}}$ - bulk concentration, $\mathrm{h}$ - diffusional distance).

2 . due to the increased saturation solubility the concentration gradient between gut lumen and blood is increased, consequently the absorption by passive diffusion (Figure 2).

According to the Kelvin equation (Anger 2005), the vapor pressure of lipid droplets in a gas phase (aerosol) increases with increasing curvature of the surface, which means decreasing particle size. Each liquid has its compound specific vapor pressure, thus the increase in vapor pressure will be influenced by the available compound-specific vapor 


\section{Surface enlargement factor}

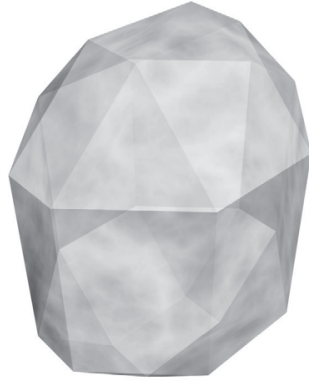

$100 \mu \mathrm{m}$

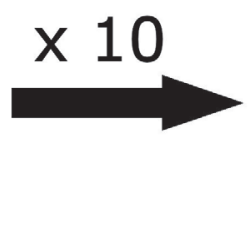

$10 \mu \mathrm{m}$

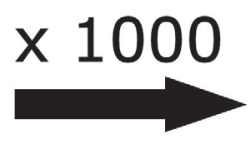

$100 \mathrm{~nm}$

Figure I Surface enlargement and increase in number of crystals by particle size diminution. Used with permission from Junghanns (2006).

pressure. The situation of a transfer of molecules from a liquid phase (droplet) to a gas phase is in principal identical to the transfer of molecules from a solid phase (nanocrystal) to a liquid phase (dispersion medium). The vapor pressure is equivalent to the dissolution pressure. In the state of saturation solubility, there is an equilibrium of molecules dissolving and molecules recrystallizing.
This equilibrium can be shifted in case the dissolution pressure increases (Figure 3), and thus the saturation solubility increases. Identical to liquids with different vapor pressures under normal conditions (micrometer droplet size), each drug crystal has a specific dissolution pressure in micrometer size. Figure 4 shows the increase in $\mathrm{c}_{\mathrm{s}}$ for the poorly soluble salt $\mathrm{BaSO}_{4}$ calculated using the Kelvin equation.

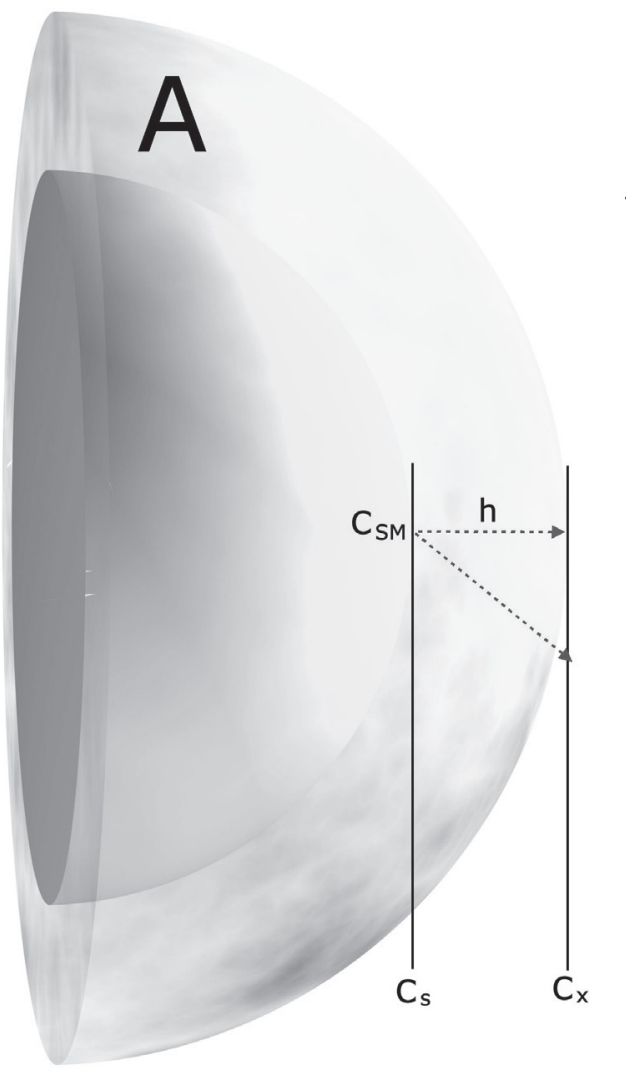

$\frac{\mathrm{C}_{\mathrm{SM}}-\mathrm{C}_{\mathrm{x}}}{\mathrm{h}} \ll \frac{\mathrm{C}_{\mathrm{SN}}-\mathrm{C}_{\mathrm{x}}}{\mathrm{h}}$

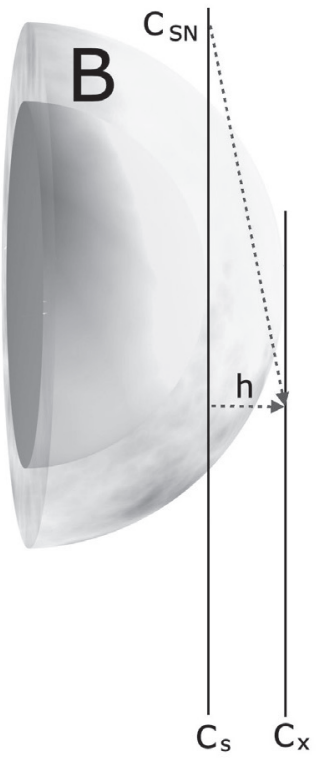

Figure 2 Comparison of a microcrystal (A) and a nanocrystal (B) and their surface curvature and concentration gradient over the diffusional distance (h).

Abbreviations: $c_{s}$, drug-saturated water at surface ( $\mathrm{M}$, microcrystal; $\mathrm{N}$, nanocrystal); $\mathrm{C}_{\mathrm{x}}$, bulk concentration at diffusional distance; $\mathrm{h}$, diffusional distance. dc / dt $\sim\left(\mathrm{c}_{\mathrm{s}}-\mathrm{c}_{\mathrm{x}}\right) / \mathrm{h}$. Used with permission from Junghanns (2006). 


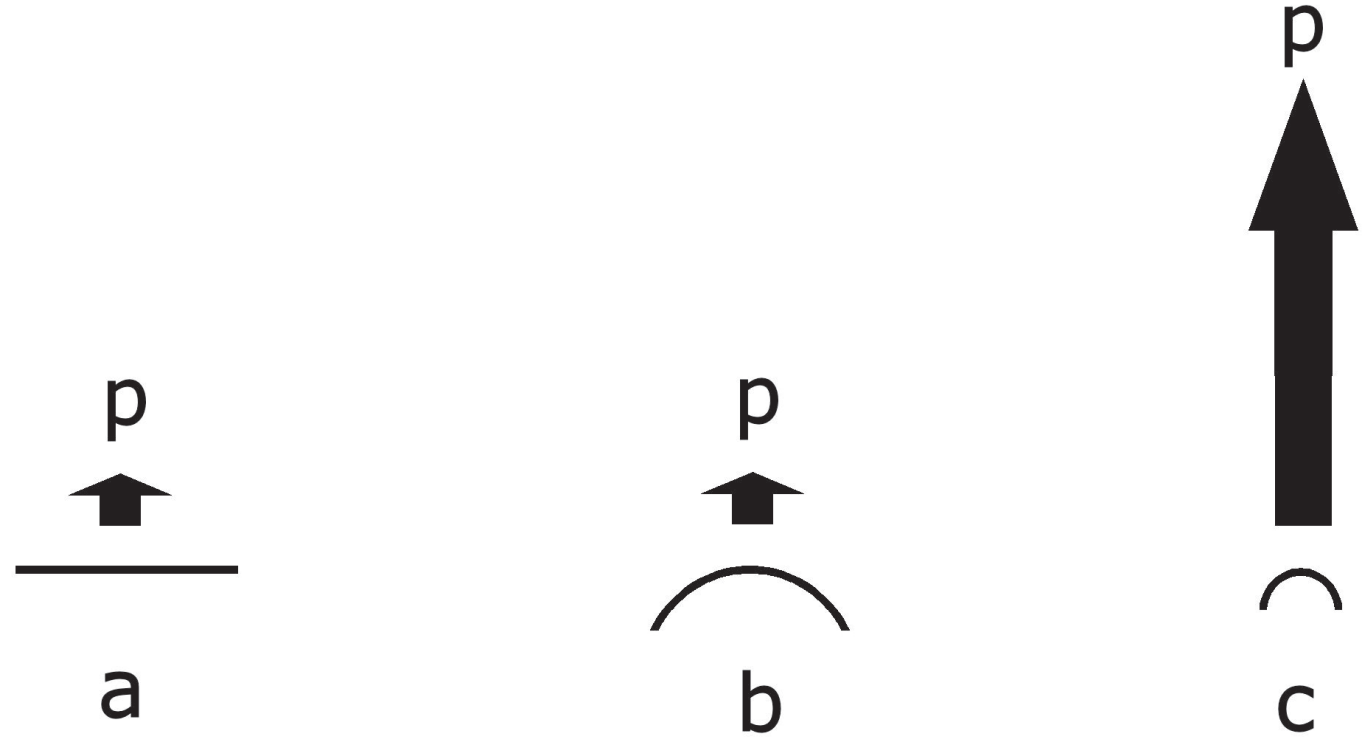

Figure 3 Increasing dissolution pressure over a flat surface, a microparticle, and a nanoparticle. Abbreviations: p, dissolution pressure; a, flat surface; b, microparticle; c, nanoparticle. Used with permission from Junghanns (2006).

\section{Advantages of an amorphous particle state}

It is well known that amorphous drugs possess a higher saturation solubility compared to crystalline drug material. A classical example from the literature is chloramphenicol palmitate. The polymorphic modification I has a solubility of 0.13 , the high energy modification II a solubility of 0.43 and the amorphous material of $1.6 \mathrm{mg} / \mathrm{ml}$ (Hancock and Parks 2000; Chong-Hui and Grant 2001). The same is valid for drug nanoparticles. Amorphous drug nanoparticles possess a higher

\section{Saturation solubility of $\mathrm{BaSO}_{4}$ in water at $293 \mathrm{~K}$}

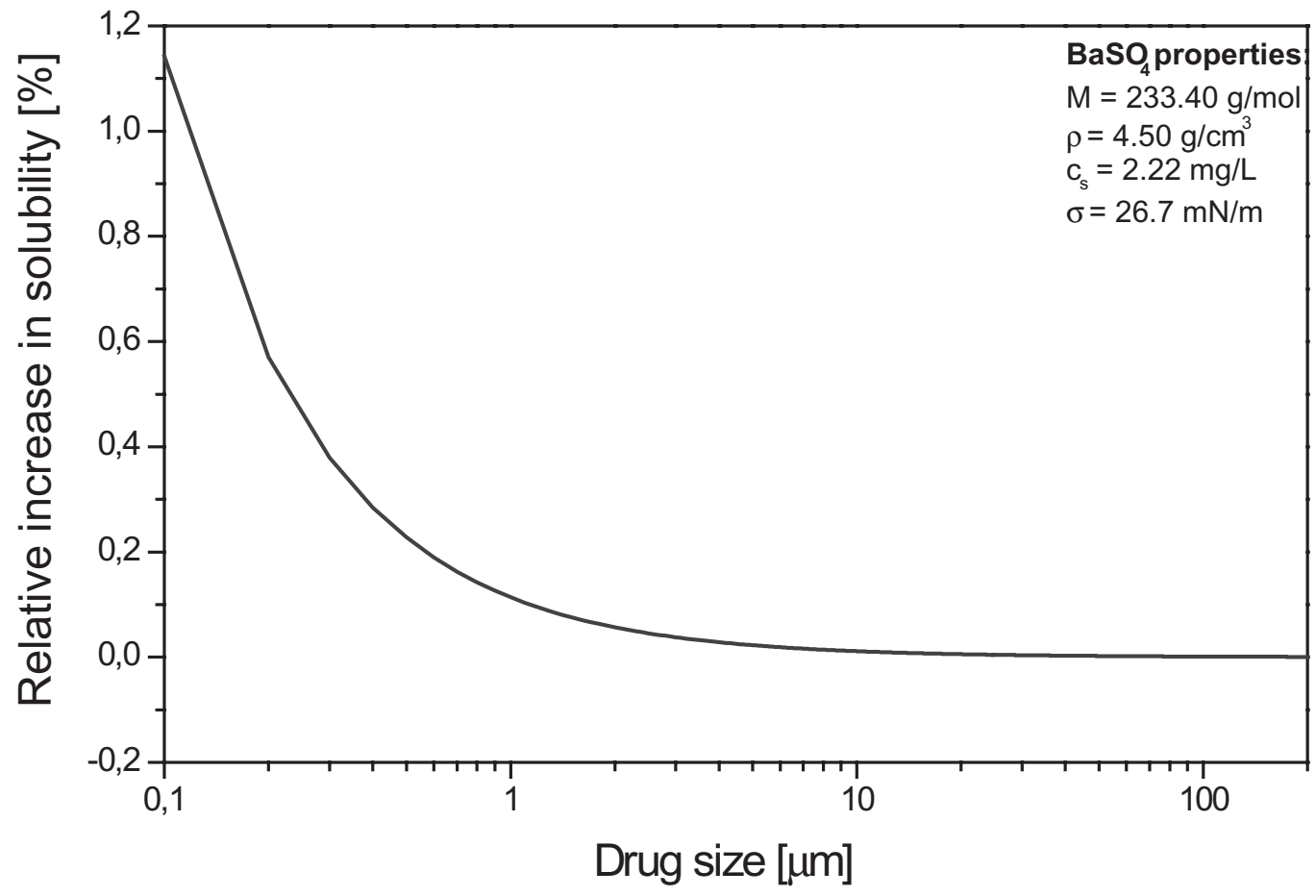

Figure 4 Increase in saturation solubility of $\mathrm{BaSO}_{4}$ in water as a function of the particle size calculated using the Kelvin equation. Used with permission from Anger (2005). 
saturation solubility compared to equally sized drug nanocrystals in the crystalline state. Therefore, to reach the highest saturation solubility increase, a combination of nanometer size and amorphous state is ideal. However, a prerequisite for utilization in pharmaceutical products is that the amorphous state can be maintained for the shelf life of the product.

Transferring all these facts to drug nanocrystals means that optimal drug nanoparticles with the highest increase in saturation solubility should have a size of eg, $50 \mathrm{~nm}$ or 20-30 nm, and be amorphous. It can be concluded that the size matters regarding the increase in saturation solubility and consequently the increase in dissolution velocity caused by a higher $\mathrm{c}_{\mathrm{s}}$. Of course, it needs to be kept in mind which blood profile is anticipated with a certain drug. In many cases a too-fast dissolution is not desired (creation of high plasma peaks, reduction of $t_{\text {max }}$ ). For many applications there is the need to combine drug nanocrystals with traditional controlled release technology (eg, coated pellets) to avoid fast dissolution, excessively high plasma peaks and premature $\mathrm{t}_{\max }$, and to reach prolonged blood levels. To summarize, the optimal drug nanocrystal size and crystalline/amorphous state will depend on:

1. Required blood profile.

2. Administration route.

3. Stability of the amorphous state during shelf life of the product.

In the case of IV-injected nanocrystals, the size should be as small as possible in case the pharmacokinetics of a solution are mimicked. In case targeting is the aim (eg, to the brain by PathFinder ${ }^{\mathrm{TM}}$ technology [Müller et al 1998] or to other organs/tissues), the drug nanocrystals should possess a certain size to delay dissolution and give them the chance to reach the blood - brain barrier (BBB) for internalization by the endothelial cells of the BBB targets in the body or other target (Kreuter et al 1995) (Table 1).

\section{Production of nanocrystals}

There are various possibilities to produce nanocrystals in the desired shape and size. Basically three principles can be

Table I Properties of nanocrystals

I - Size below I $\mu \mathrm{m}$

2 - $100 \%$ drug, no carrier

3 - Generally needed to be stabilized

4 - Crystalline or amorphous structure

5 - Increase of dissolution velocity

6 - Increase in saturation solubility

7 -Amorphous particle state offers advantages used: milling, precipitation methods and homogenization methods, as well as a combination thereof. The industrially relevant methods are the top down technologies, ie, starting from a large-size drug powder to be reduced in size. The bottom up technologies (ie, starting from a dissolved molecule, precipitation) are currently - to our knowledge - not used in the production of commercial products. Reasons may include the need for solvent removal, the difficulty in controlling the process, and the fact that many poorly soluble drugs are poorly soluble not only in aqueous, but also organic media.

\section{Precipitation methods}

One of the first precipitation methods is the preparation of hydrosols, which was developed by Sucker, with the intellectual property owned by Sandoz (nowadays Novartis) (List and Sucker 1988; Gassmann et al1994). The technology is basically a classical precipitation process known as "via humida paratum" (VHP). This VHP. process was already described in the old pharmacopeia to prepare ointments containing finely dispersed, precipitated drugs. The drug is dissolved in a solvent and subsequently added to a nonsolvent, leading to the precipitation of finely dispersed drug nanocrystals. One needs to bear in mind that these nanocrystals need to be stabilized in order not to grow to the micrometer range. In addition, the drug needs to be soluble in at least one solvent, which creates problems for newly developed drugs that are insoluble in both aqueous and organic media. These are some reasons why, to our knowledge, this technology has not been applied to a product as yet.

Another precipitation method is the preparation of amorphous drug nanoparticles, for example, as carotene nanoparticles in the food industry (Shackleford et al 2003), eg, Lucarotin ${ }^{\circledR}$ or Lucantin ${ }^{\circledR}$ (BASF). A solution of the carotenoid, together with a surfactant in a digestible oil, are mixed with an appropriate solvent at a specific temperature. To obtain the solution a protective colloid is added. This leads to an $\mathrm{O} / \mathrm{W}$ two phase system. The carotenoid stabilized by the colloid localizes in the oily phase. After lyophilization X-ray analyzes shows that approximately $90 \%$ of the carotenoid is in an amorphous state. This technology is used for pharmaceuticals by Soliqs (Ludwigshafen, Germany) and advertised under the trade name NanoMorph ${ }^{\circledR}$.

\section{Milling methods}

The classical NanoCrystals ${ }^{\circledR}$ technology uses a bead or a pearl mill to achieve particle size diminution. Ball mills are already known from the first half of the 20th century for the 
production of ultra fine suspensions (Pahl 1991). Milling media, dispersion medium (generally water), stabilizer and the drug are charged into the milling chamber. Shear forces of impact, generated by the movement of the milling media, lead to particle size reduction. In contrast to high pressure homogenization, it is a low energy milling technique. Smaller or larger milling pearls are used as milling media. The pearls or balls consist of ceramics (cerium or yttrium stabilized zirconium dioxide), stainless steel, glass or highly crosslinked polystyrene resin-coated beads. Erosion from the milling material during the milling process is a common problem of this technology. To reduce the amount of impurities caused by erosion of the milling media, the milling beads are coated (Bruno et al 1992). Another problem is the adherence of product to the inner surface area of the mill (consisting mainly of the surface of the milling pearls and the surface of the mill itself).

There are two basic milling principles. Either the milling medium is moved by an agitator, or the complete container is moved in a complex movement leading consequently to a movement of the milling media. When one assumes that $76 \%$ of the volume of the milling chamber (maximum value at hexagonal packaging) are going to be filled with milling material, larger batches are difficult to produce when moving the complete container, so mills using agitators are used for large sized mill for large batches. The milling time depends on many factors such as the surfactant content, hardness of the drug, viscosity, temperature, energy input, size of the milling media. The milling time can last from about 30 minutes to hours or several days (MeriskoLiversidge et al 2003). This technology is an important particle size reduction technology which is proven by four FDA-approved drugs using it, which will the subject later in this text.

\section{Homogenization methods}

When producing nanocrystals using homogenization methods, there are three important technologies namely: Microfluidizer technology (IDD-PTMTM technology), Piston gap homogenization in water (Dissocubes ${ }^{\circledR}$ technology) and in water mixtures or in nonaqueous media (Nanopure ${ }^{\circledR}$ technology).

The Microfluidizer technology can generate small particles by a frontal collision of two fluid streams under pressures up to 1700 bar (Bruno and McIlwrick 1999). This leads to particle collision, shear forces and also cavitation forces (Tunick et al 2002). It can be achieved with jet stream homogenizers such as the microfluidizer (Microfluidizer ${ }^{\circledR}$, Microfluidics Inc.). The collision chamber can be designed in two shapes, being either Y-type or Z-type. Surfactants are required to stabilize the desired particle size. Unfortunately ,a relatively high number of cycles (50 to 100 passes) are necessary for a sufficient particle size reduction. SkyePharma Canada Inc. (formerly RTP Inc.) uses this principle for their Insoluble Drug Delivery - Particles (IDD-PTM) technology to achieve the production of submicron particles of poorly soluble drugs.

In contrast, the Dissocubes ${ }^{\circledR}$ technology employs piston-gap homogenizers. The technology was developed by Müller and colleagues $(1995,1999)$ and later acquired by SkyePharma PLC. It is the production of nanoparticle suspensions in water at room temperature. A drug powder is dispersed in an aqueous surfactant solution and subsequently forced by a piston through the tiny homogenization gap with pressures ranging up to 4000 bar, typically 1500 to 2000 bar (Figure 5). The width of the homogenization gap, depending on the viscosity of the suspension and the applied pressure, ranges from approximately. 5 to $20 \mu \mathrm{m}$ (Möschwitzer 2005). The resulting high streaming velocity of the suspension causes an increase in the dynamic pressure which is compensated by a reduction in the static pressure below the vapor pressure of the aqueous phase (according to Bernoulli's law [Müller et al 1995]). Formation of gas bubbles occurs because the water starts boiling at room temperature. These gas bubbles collapse immediately when the liquid leaves the homogenization gap being again under normal air pressure of 1 bar.

This phenomenon of formation and implosion of the gas bubbles is called cavitation resulting in shockwaves. The drug particles are reduced in size due to high shear forces, turbulent flow and the enormous power of these shockwaves (Muller et al 2001).

Of course, the use of water can have disadvantages, eg, hydrolysis of water-sensitive drugs and problems during subsequent drying steps (such as the removal of too much water). When applied to drugs with a low melting point, the drying process may quire expensive techniques like lyophilization. Therefore the technology is most suitable for the formulation of aqueous suspensions of nanocrystals (Figure 6) (Müller et al 2003).

Another approach using the piston-gap homogenizer is the Nanopure ${ }^{\circledR}$ technology, owned and developed by PharmaSol GmbH in Berlin. The technology uses dispersion media with a low vapor pressure and optionally homogenization at low temperatures. The cavitation in the homogenization gap is very little or nonexistent. Even without cavitation, the size diminution was sufficient (Bushrab and Müller 2003). The 

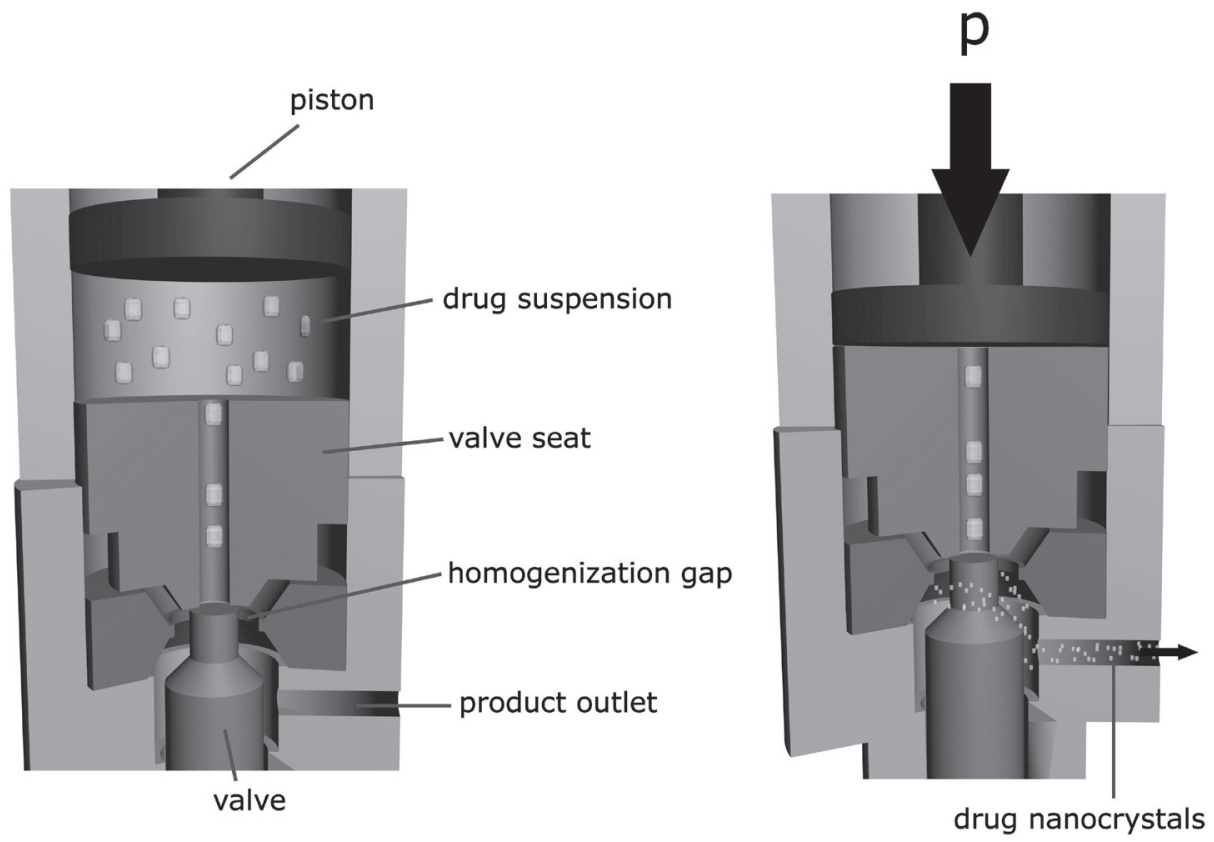

Figure 5 Basic principle of high pressure homogenization using a piston gap homogenizer. Used with permission from Junghanns (2006).

remaining shear forces, particle collisions and turbulences are sufficient to achieve nanoparticles. The optional low temperatures while homogenizing allow the processing of temperature labile drugs (Müller et al 2002). It is possible to carry out the whole process in nonaqueous media to protect drugs from hydrolysis. Usage of oils, PEG or hot-melted polyethylene glycols can be directly filled into gelatin or HPMC capsules (Keck et al 2004).

In order to give a complete overview of the available technologies the following methods are also available. The company Baxter uses for its NanoEdge ${ }^{\mathrm{TM}}$ technology a precipitation step with subsequent annealing step by

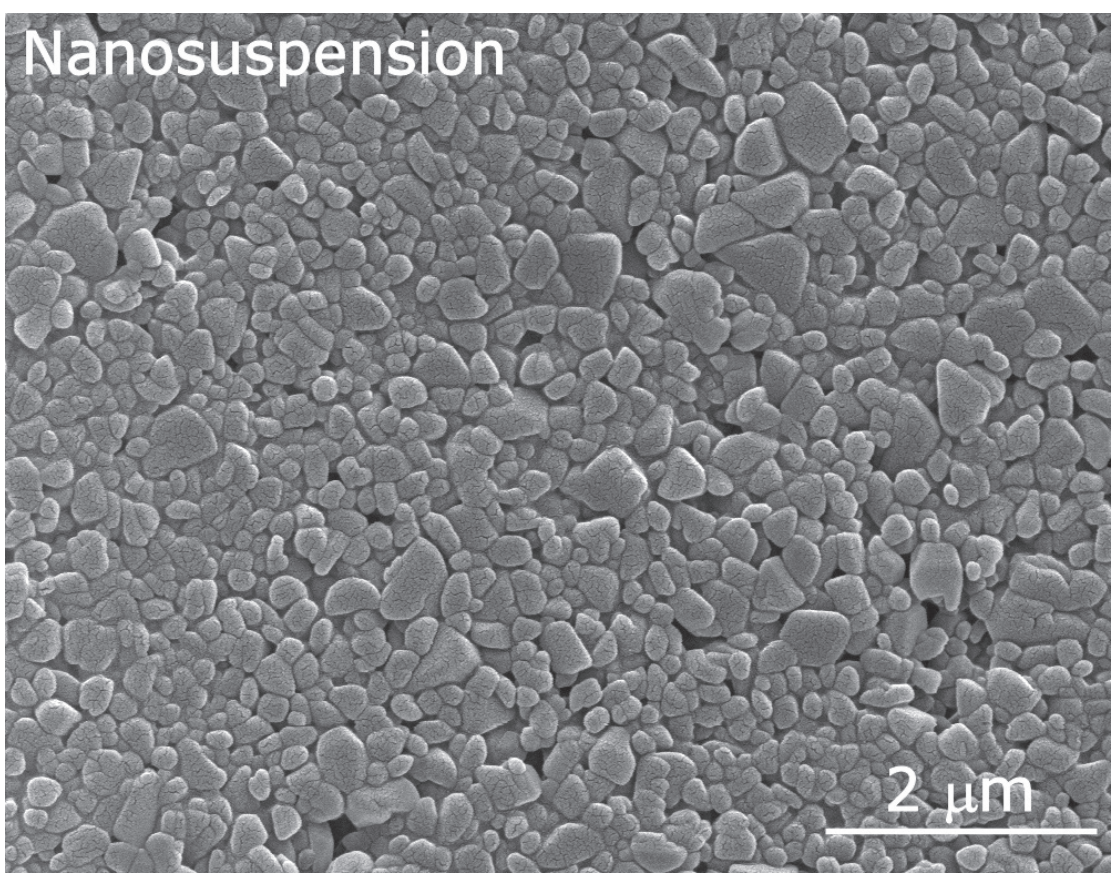

Figure 6 Scanning electron microscopic picture of a nanosuspension prepared with high pressure homogenization. Used with permission from Möschwitzer (2005). 
applying high energy, eg, high shear and/or thermal energy (Kipp et al 2003). PharmaSol uses in its Nanopure XP technology a pre-treatment step with subsequent homogenization to produce particles well below $100 \mathrm{~nm}$ (Müller and Moeschwitzer 2005). Drug nanocrystals with a size of about $50 \mathrm{~nm}$ and below are distinctly smaller than the wavelength of the visible light, and so the nanosuspensions are translucent.

Among other technologies, the following supercritical fluid methods are mentioned for reasons of completeness only. Rapid expansion of supercritical solution (RESS), rapid expansion from supercritical to aqueous solution (RESAS), solutionenhanced dispersion by the supercritical fluids (SEDS), spray freezing into liquid (SFL), evaporative precipitation into aqueous solution (EPAS), and aerosol solvent extraction (ASES) (Müller and Bleich 1996; Lee et al 2005).

\section{Products in the market}

All nanocrystals in the first four products were produced using the pearl mill technology by Elan Nanosystems. Prerequisite was the availability of production facilities at sufficiently large scale. In general candidates of first choice for Nanocrystal ${ }^{\circledR}$ technology are drugs with a relatively low dose (Table 2).

\section{Rapamune $^{\circledR}$}

Rapamune $^{\circledR}$ contains sirolimus (SRL, rapamycin) as the active drug, which is derived from Streptomyces hygroscopicus (actinomycetes) (Figures 7,8). SRL is a macrocyclic immunosuppressive drug with a molecular weight of 914.2 and is related to tacrolimus which is produced from different species of Streptomyces.
SRL is being used mostly in a combination with cyclosporine or steroids to avoid organ rejection in patients after a kidney transplant. In cardiology SLR is used because of its antiproliferative effect to avoid a reoccurring constriction (restenosis) caused by a hyperplasia of the inner vascular after implantation of a stent into the vessels around the heart.

The mechanism of action of SLR is different from cyclosporine and tacrolimus. SLR inhibits several cytokine induced signal transduction pathways by complexing the mTOR (mammalian Target of Rapamycin) protein, which is a 282 kDA phosphatidyl 3 kinase. Therefore the subsequent activation and the protein synthesis of the S6-Kinase (p70SK6) is not triggered and the activation of the ribosomal protein S6 does not occur. The inhibition of mTOR circumvents the activation of the p34cdc2 kinase and thus the complexation with Cyclin E. This results in an inhibition of the T-cell transfer from the G1-phase to the S-phase of the cell-cycle (Sehgal 1998).

Rapamune was the first marketed product introduced in 2000 by Wyeth Pharmaceuticals (Madison, NJ). It is available in two formulations, as oral suspensions and as a tablet. The tablet has the advantage of being more userfriendly. Comparing the oral bioavailability of solution and nanocrystal tablet, the bioavailability of the nanocrystals is $21 \%$ higher compared to the solution. The oral single dose of Rapamune is 1 or $2 \mathrm{mg}$, the total tablet weight being approximately $365 \mathrm{mg}$ for $1 \mathrm{mg}$ formulation and approximately. $370 \mathrm{mg}$ for the $2 \mathrm{mg}$ formulation. This means it contains a very low percentage of its total weight as nanocrystals. An important point is that the drug nanocrystals are released from the tablet as ultra fine nanosuspension. In the event that

Table 2 Advantages and disadvantages of different methods for the production of nanocrystals

\begin{tabular}{lll}
\hline Technology & Advantages & Disadvantages \\
\hline Precipitation & - finely dispersed drug & - needs to be stabilized \\
& - good control of desired size & - organic solvent residue \\
Milling & - not universally applicable, only drugs with certain \\
& properties are possible (eg, soluble in at least one \\
& - low energy technique & solvent) \\
& & - residue from milling media \\
Homogenization & & - can be a slow process (several days) \\
& & - needs to be stabilized \\
& - large batches difficult to produce due to size of \\
& - nilling chamber \\
& - fast method (several minutes possibly) & - high energy technique \\
& - water free production possible & - great experience needed \\
\hline
\end{tabular}




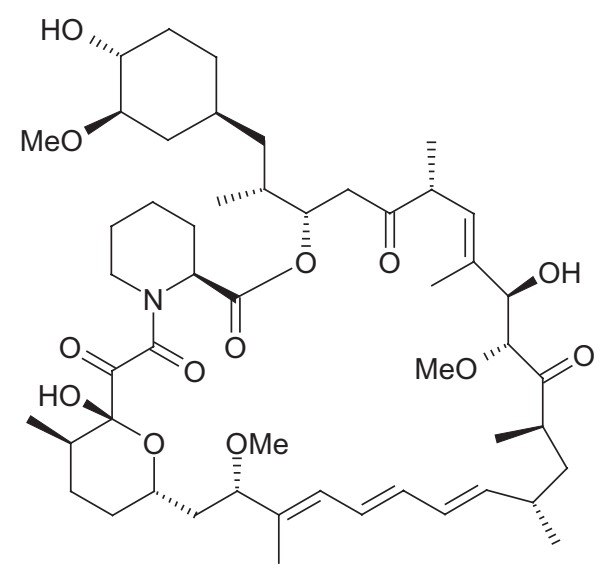

Figure 7 Structural formula of sirolimus.

crystal aggregation takes place to a pronounced extent, the dissolution velocity and subsequently the oral bioavailability of the BSC II drugs will be reduced. Therefore, there is an upper limit to load tablets with nanocrystals. In case the limit is exceeded and nanocrystals get in contact with each other within the excipient mixture of the tablet, the nanocrystals might fuse to larger crystals under the compression pressure during tablet production. For drugs with a low oral single dose such as sirolimus in Rapamune, incorporation into tablets causes few or no problems. A total nanoparticle load of less than $1 \%$ is well below the percentage being critical (Bushrab 2005).

The main advantages of the nanocrystal technology in this product are the user friendliness and the higher bioavailability in comparison to the oral solution. As discussed previously, a smaller particle size leads to greater solubility and larger surface area, consequently increased dissolution velocity and thus greater bioavailability.

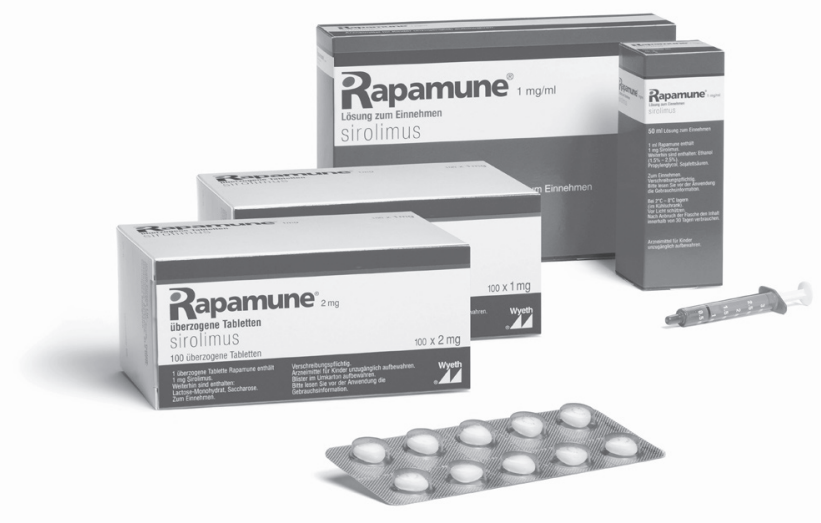<smiles>C[C@@H](O[C@@H]1OCCN(Cc2n[nH]c(=O)[nH]2)[C@H]1c1ccc(F)cc1)c1cc(C(F)(F)F)cc(C(F)(F)F)c1</smiles>

Figure 9 Structural formula of aprepitant.

\section{Emend $^{\circledR}$}

The second product on the market was Emend ${ }^{\circledR}$, introduced in 2001 by Merck (Winehouse Station, NJ) (Figures 9, 10). The drug is aprepitant, used for treatment of emesis (single dose is either 80 or $125 \mathrm{mg}$ ).

Aprepitant is a selective, high-affinity antagonist of human substance P/neurokinin 1 (NK 1) receptors. Aprepitant has little or no affinity for serotonin (5-HT 3), dopamine, and corticosteroid receptors, the targets of existing therapies for chemotherapy-induced nausea and vomiting (CINV).

Aprepitant has been shown in animal models to inhibit emesis induced by cytotoxic chemotherapeutic agents, such as cisplatin, via central actions. Aprepitant augments the antiemetic activity of the 5-HT 3-receptor antagonist ondansetron and the corticosteroid dexamethasone and inhibits both the acute and delayed phases of cisplatin-induced emesis.

Aprepitant will only be absorbed in the upper gastrointestinal tract (Shimizu 2003). Bearing this in mind nanoparticles proved to be ideal to ideally exploit this narrow absorption window. The large increase in surface area due to nanonization leads to rapid in vivo dissolution, fast absorption and increased bioavailability (Möschwitzer and Müller 2004a, 2004b). The

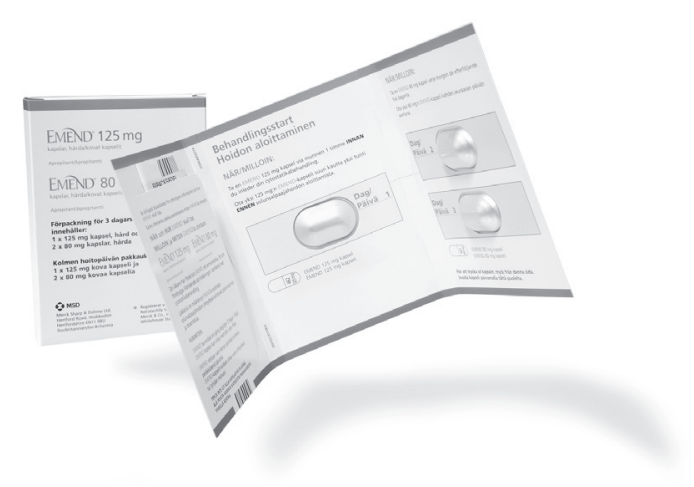

Figure 8 Packaging of Rapamune ${ }^{\oplus}$.

Figure 10 Packaging of Emend $d^{\circledR}$. 
formulation of a tablet from micronized bulk powder made much higher doses necessary, leading to increased side effects (eg, other serotonin receptor induced effects like dizziness) (Wua et al 2004). The drug nanocrystals are contained within a hard gelatin capsule as pellets. Aprepitant was formulated this way in order to make the drug easy to handle by healthcare providers and patients as capsules. In addition, the pellets can be administered via a stomach tube. Currently studies are being undertaken to evaluate the change in pharmacokinetics (if any) between the pellets and the capsules. One needs to bear in mind that a higher loading of the tablet with more than $125 \mathrm{mg}$ drug in a $400 \mathrm{mg}$ tablet is near the critical amount, which is about $30 \%$. If the total drug content exceeds $30 \%$, the possibility of drug nanocrystals directly touching each other and fusing to larger crystals is enhanced. There are special methods and technologies required to produce high nanocrystal-loaded tablets. By applying this, up to $90 \%$ nanocrystal powder would be loaded into tablets (Möschwitzer and Müller 2005).

This example of aprepitant demonstrates once again the importance of an increased bioavailability through nanonization. In case of a drug with a narrow absorption window which is also poorly soluble it is important to reduce the particle size to a size threshold that will make the drug bioavailable by enhancing the solubility.

\section{Tricor $^{\circledR}$}

Tricor $^{\circledR}$ is being marketed by Abbott Laboratories and the active ingredient is fenofibrate, being available in $48 \mathrm{mg}$ and $145 \mathrm{mg}$ tablets (Figures 11, 12). Tricor is indicated as adjunctive therapy to diet in adult patients with primary hypercholesterolemia or mixed dyslipidemia (Fredrickson types IIa and IIb) to increase high-density lipoprotein cholesterol (HDL-C), reduce triglycerides (TG), reduce low-density lipoprotein cholesterol (LDL-C), reduce total cholesterol (Total-C), and reduce apolipoprotein B (Apo B).

Fenofibrate is metabolized into fenofibric acid and activates the peroxisome proliferator-activated receptor $\alpha$ (PPAR $\alpha$ ). Fenofibrate increases the lipolyses and the elimination of

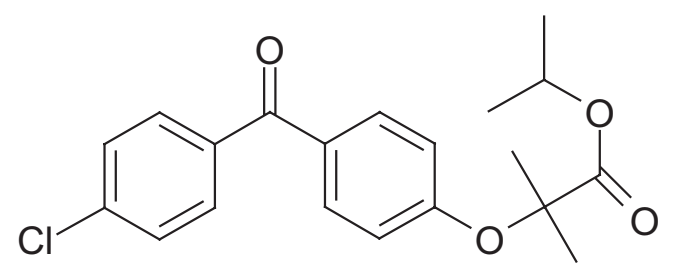

Figure I I Structural formula of fenofibrate.

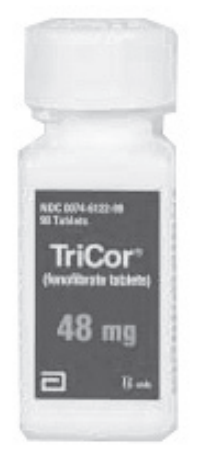

Figure I 2 Packaging of Tricor $^{\circledR}$.

TH-rich particles from the plasma by activating the lipoprotein lipase and reducing the production of apoprotein C-III, which is an inhibitor of the lipoprotein lipase activity.

The subsequent fall in TG produces an alteration in size and composition of LDL from small dense particles (thought to be atherogenic due to their susceptibility to oxidation) to large buoyant particle. These particles have a greater affinity for cholesterol receptors and are catabolized rapidly (Witztum 1996).

In types IIa and IIb hyperlipidemia, LDL-C also decreases, in contrast to type IV hyperlipidemia where LDL-C often increases. The activation of PPAR $\alpha$ also induces an increase in the synthesis of apoproteins A-I, A-II and HDL-C (Investigators 2001).

In normal and hyperuremic individuals, fenofibrate also reduces the serum uric acid levels by increasing the urinary excretion of uric acid (TriCor ${ }^{\circledR}$ tablets package insert; Abbott Labs, Wiesbaden-Delkenheim, Germany).

In general, the uptake from of the gut lumen and thus the bioavailability of fenofibrate is depending on whether the patient is in the fed or nonfed state. The absorption of fenofibrate in fed patients is up to $35 \%$ higher than in nonfed patients. The nanocrystal technology makes the fenofibrate independent of meals. Plasma levels in fed and fasting condition are bioequivalent (data on file, Abbott Labs).

Fenofibrate is a lipophilic compound and practically insoluble in water. Having no ionizable group, the solubility of fenofibrate was not influenced by changes in $\mathrm{pH}$ value through the application of food. The enhanced absorption of fenofibrate in fed patients can be explained with the availability of lipids and other surfactants (eg, cholesterol) in the food, thus solubilizing the fenofibrate. By nanonizing the drug, the solubility is enhanced, making it bioequivalent in fed and fasting conditions.

Another product using nanocrystals to make an advanced fenofibrate is Triglide ${ }^{\circledR}$, which is produced using the 
IDD-P ${ }^{\circledR}$-technology (as discussed before) from Skyepharma and is marketed by Sciele Pharma Inc (Atlanta, GA).

\section{Megace $\mathrm{ES}^{\circledR}$}

In Megace $\mathrm{ES}^{\circledR}$ (ES stands for Enhanced Stability) (megestrol acetate) introduced by Par Pharmaceutical Companies, Inc. (Spring Valley, NY), who licensed the Megace name from Bristol-Myers Squibb (New York, NY), the Nanocrystal technology leads to several advantages (Figures 13, 14).

Megestrol was synthesized in England in 1963. Initially developed as a contraceptive, it was first evaluated in breast cancer treatment in 1967. Megestrol is a synthetic progestin and has the same physiologic effects as natural progesterone. The biochemical mechanism of progestin antitumor activity is not well known but may involve interaction with progesterone and glucocorticoid receptors, and androgenic properties. Megestrol also has direct cytotoxic effects on breast cancer cells in tissue culture and suppresses luteinizing hormone release from the pituitary. It is mainly used to improve weight gain and appetite in patients undergoing chemotherapy or suffering from an HIV infection. It can also be used to treat psychologically induced anorexia. The precise mechanism of megestrol's antianorexic and anticachetic effects is unknown (Prescribing Information 2005).

Megestrol is well absorbed in the gastrointestinal tract but absorption varies. A bioavailability study comparing the peak plasma concentration and extent of absorption of Megace ES and megestrol acetate oral suspension revealed that in unfed patients, the bioavailability of Megace ES is minimally reduced while there was a substantial food effect for megestrol acetate oral suspension (Femia 2005).

The improved rate of dissolution again resulting from the particle dimensions in the nanometer range leads to an enhanced bioavailability in people in fasted state (NanoCrystal ${ }^{\circledR}$-Technology-Group 2005).

The nanonized drug can be formulated in less volume, so the single dose the patient has to take (daily dose $625 \mathrm{mg}$

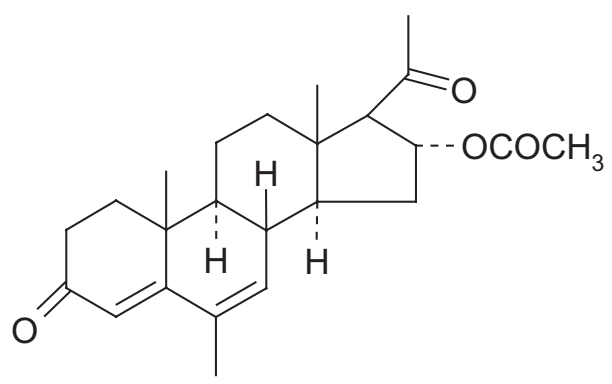

Figure 13 Structural formula of megestrol acetate.

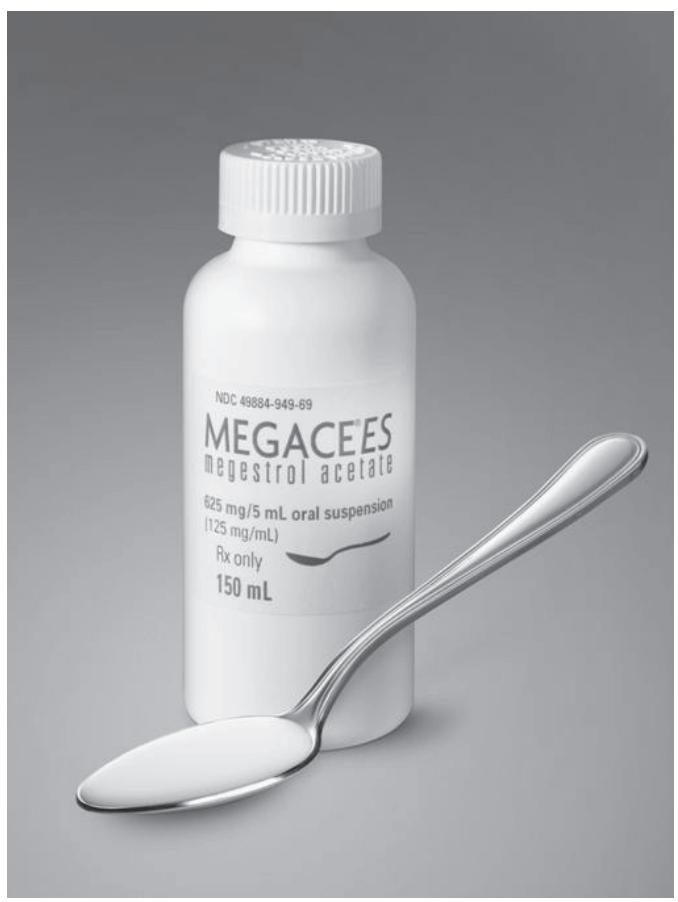

Figure I4 Packaging of Megace ${ }^{\circledR}$ ES.

of megestrol in $5 \mathrm{ml}$ of fluid) is reduced by the factor four compared to the oral solution available. This reduced volume and the improved bioavailability lead to a better patient compliance due to the possibility of flexible dosing in order to provide effective appetite stimulation and weight gain.

Another advantage is the reduced viscosity of the Megace ES formulation, which also leads to increased patient compliance. This viscosity reduction is a direct effect of the reduction of the particle size (no or little viscosity enhancement necessary to prevent sedimentation) (Data on file. Par Pharmaceutical Companies, Inc.) (Table 3).

\section{Products in pipeline}

In general, it can be stated that the advantages of the nanocrystal technology can be applied to many other poorly soluble drugs as well. There are already several products close to being marketed or in clinical trials.

Information about these drugs and products is sparingly available due to high risks for knowledge leaks and fear of competitors in the pharmaceutical industry, but the following examples give an indication of potential future products:

\section{Semapimod ${ }^{\circledR}$ (cytokine, pharmasciences)}

Semapimod ${ }^{\circledR}$ is a synthetic guanylhydrazone that inhibits 1 ) signal transduction pathways by preventing phosphorylation of p38 MAP kinase and JNK; 2) production of the 
Table 3 Overview of current state of development of drugs using the Nanocrystal ${ }^{\circledR}$ technology or others

\begin{tabular}{|c|c|c|c|c|c|}
\hline Tradename & Drug & Indication & Applied technology & Company & Status \\
\hline Rapamune $^{\circledR}$ & Rapamycin & Immunesuppressive & Nanocrysta $\left.\right|^{\circledR}$ élan & Wyeth & marketed \\
\hline Emend $^{\circledR}$ & Aprepitant & Anti emetic & Nanocrysta $\left.\right|^{\circledR}$ élan & Merck & marketed \\
\hline Tricor $^{\circledast}$ & Fenofibrate & Hypercholesterolemia & Nanocrysta $\left.\right|^{\circledR}$ élan & Abbott & marketed \\
\hline Megace $\mathrm{ES}^{\circledR}$ & Megestrol & Anti anorexic & Nanocrysta ${ }^{\circledR}$ élan & $\begin{array}{l}\text { Par Pharmaceutical } \\
\text { Companies }\end{array}$ & marketed \\
\hline Triglide ${ }^{\circledR}$ & Fenofibrate & Hypercholesterolemia & IDD-P ${ }^{\circledR}$ Skyepharma & Sciele Pharma Inc. & marketed \\
\hline Semapimod ${ }^{\circledR}$ & Guanylhydrazone & TNF- $\alpha$ inhibitor & own & Cytokine Pharmasciences & Phase II \\
\hline Paxceed $^{\circledR}$ & Paclitaxel & Anti inflammatory & unknown & Angiotech & Phase III \\
\hline Theralux ${ }^{\circledR}$ & Thymectacin & Anti cancer & Nanocrysta $\left.\right|^{\circledR}$ élan & Celmed & Phase II \\
\hline Nucryst ${ }^{\circledR}$ & Silver & Anti bacterial & own & Nucryst Pharmaceuticals & Phase II \\
\hline
\end{tabular}

Used with permission from Junghanns (2006).

proinflammatory cytokines TNF-alpha, IL-1, IL-6. MIP-1 alpha, MIP-1 beta; and 3) production of nitric oxide. These signal transduction pathways and proinflammatory molecules are known to be active in various inflammatory and autoimmune diseases. Semapimod may therefore have widespread applications in these diseases. In animal models, Semapimod has shown protective activity against a wide variety of conditions, ranging from stroke to inflammatory bowel disease. A Phase I study in cancer patients demonstrated the safety of the compound and confirmed its activity in preventing the synthesis of TNF-alpha in humans. CPSI conducted successful proof-of-principle studies in psoriasis and Crohn's disease. The company also employs the nanocrystal technology from Elan Nanosystems in order to make this poorly soluble drug bioavailable (cited after http://www. cytokinepharmasciences.com).

\section{PAXCEED TM}

Angiotech Pharmaceuticals Inc, (Vancouver, BC) has developed an intravenous (or systemic) treatment for rheumatoid arthritis. Treating patients with chronic inflammatory diseases require that side effects of systemic treatments be minimized. They have produced a cremophor EL-free systemic paclitaxel formulation, PAXCEED ${ }^{\mathrm{TM}}$ (paclitaxel, Angiotech Pharmaceuticals, Inc.), for patients with active, widespread diseases. This formulation reduces the incidence of hypersensitivity reactions. In addition, the doses of PAXCEED ${ }^{\text {TM }}$ used for these indications are significantly lower when used as an anti-proliferative.

PAXCEED $^{\mathrm{TM}}$ is a metalloproteinase inhibitor and therefore has the potential to not only stop inflammation, but also protect the cartilage. In addition, PAXCEED ${ }^{\text {TM }}$ is synergistic, not competitive, to recently developed antiTNF therapies.
At this moment there is no information available which nanotechnology was used to produce the resulting nanocrystals. The low solubility of Paclitaxel and the proclaimed absence of Cremophor EL give a good indication (cited after http://www.angiotech.com).

\section{Theralux ${ }^{\mathrm{TM}}$}

Thymectacin is currently in Phase I/II clinical development. Theralux ${ }^{\mathrm{TM}}$ (thymectacin, Celmed BioSciences Inc, Saint-Laurent, QC), a photodynamic-based therapy, is being evaluated in three therapeutic areas: the prevention of graftversus-host disease (GvHD), the treatment of autoimmune diseases by extracorporeal photochemotherapy (ECP) and the eradication of cancerous cells from bone marrow transplants in non-Hodgkin's lymphoma (NHL). The company also employs the nanocrystal technology from Elan Nanosystems. Thymectacin is poorly soluble and thus needs to be formulated as nanocrystals to become bioavailable.

The Theralux system consists of a photosensitive drug and a device designed to eliminate certain unwanted cells (used outside the body). The drug, TH9402, is Celmed's proprietary product that is preferentially retained in cancer cells and activated T cells. When TH9402 is administered to a stem cell graft, it enters and is retained in the cancerous cells and activated $\mathrm{T}$ cells, but not other normal cells such as stem cells, progenitors and precursors. When the cells retaining the drug are exposed to visible light using Celmed's Theralux device, the drug undergoes photodynamic activation leading to the death of the unwanted cells. The process is conducted ex vivo (outside the body), thus minimizing side effects and toxicity. Once the blood sample has been purged of the unwanted cells, it is reinfused into the patient, who meanwhile has undergone high-dose chemotherapy (cited after: http://www.newbiotics.com). 


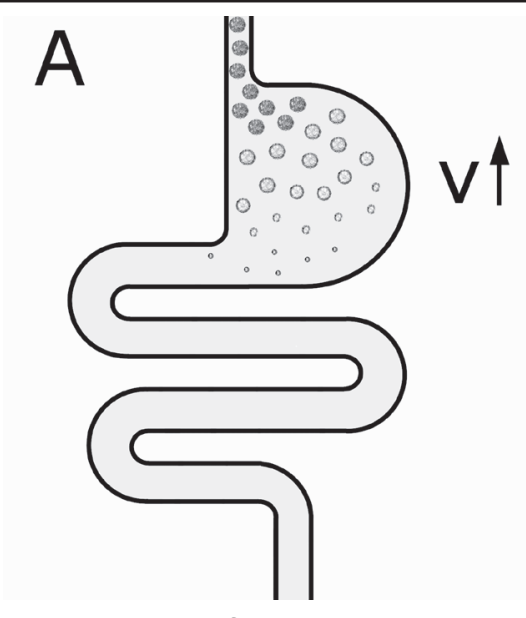

Dissolution so fast to mimick adminstered solution (eg, Rapamune)

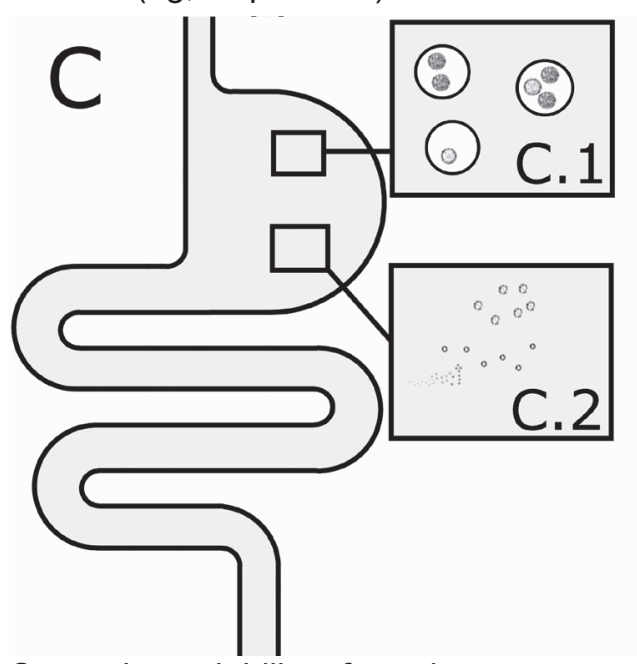

Saturation solubility of poorly water soluble but lipid soluble drug as NC in water as high as drug dissolved in food (fats/oils) (eg, Tricor)

C.1 fat/oil droplets with drug

C.2 NC drug in water

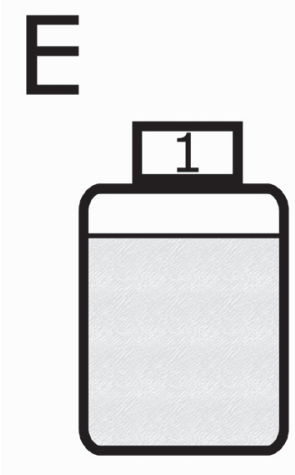

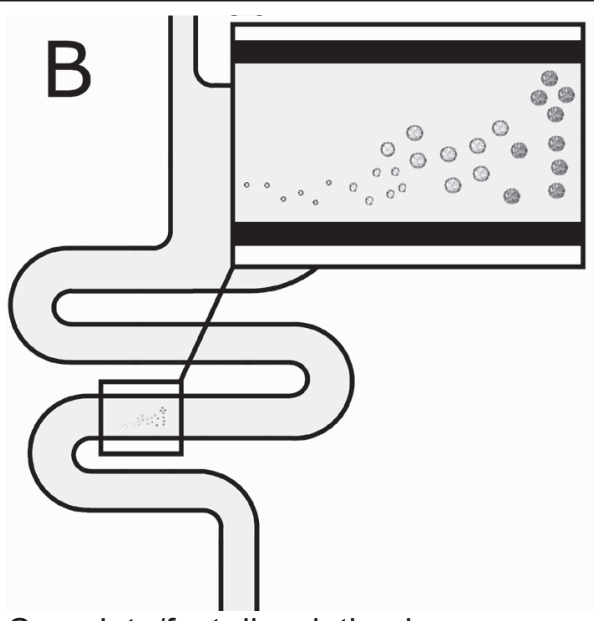

Complete/fast dissolution in a narrow absorption window (eg, Emend)

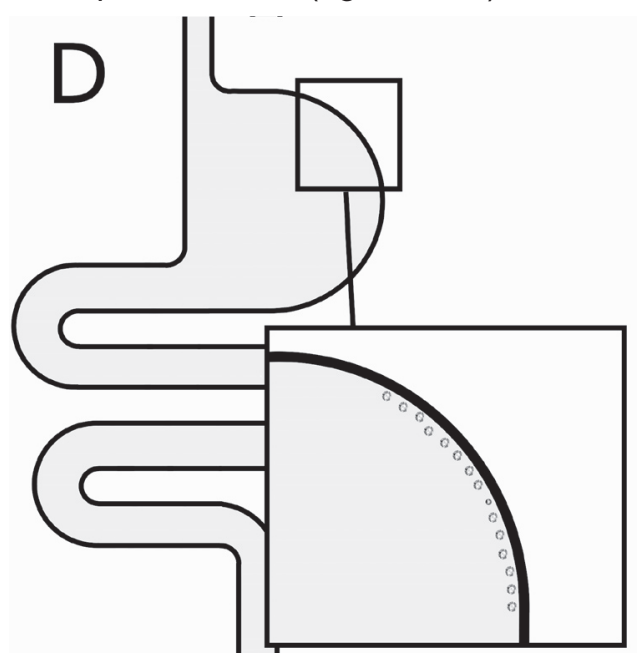

Adhesiveness to gut wall avoids effects of fed/fasted condition (ie, no or little variation in bioavailability) (eg, Tricor)
$1=$ solution of drug in $20 \mathrm{ml}$

2=concentrated Nanosuspension $(12.5 \%)$ in $5 \mathrm{ml}$

Both flasks contains the same drug dose, eg, $625 \mathrm{mg}$

Compared with solutions Nanosuspension can administer a high dose of drug in a very small volume (=volume reduction) but provide an identical bioavailability as a solution (eg, Megace ES) Nanosuspension with a $40 \%$ solid content can be produced 


\section{NUCRYST ${ }^{\circledR}$}

With their own nanotechnology, Nucryst Pharmaceuticals (Wakefield, MA) has developed a way to produce silver nanoparticles which can be used in antimicrobiological coatings for medical use. They are also working on their substance NPI 32101 in a cream formulation, which is in clinical development to treat atopic dermatitis (Bhol et al 2004; Bol and Schechter 2005a). NPI 32101 is free standing silver nanocrystals, which can be combined with pharmaceutical carriers such as creams, gels, solutions, or tablets to form prescription drugs. Laboratory studies have demonstrated NPI 32101's anti-inflammatory and antimicrobial properties (Bhol and Schechter 2004; Lyczak and Schechter 2005). NUCRYST's in vitro and in vivo research results suggest that NPI 32101 offers great promise for a range of commercial pharmaceutical products. The NPI 32101 is currently in clinical phase II (Bhol and Schecter 2005b).

Apart from the products already mentioned there are drugs such as naproxen which are also being investigated for formulation as nanosuspension or nanocrystals (eg, for fast action onset and reduced gastric irritancy) (Liversidge and Conzentino1995). However, it requires more sophisticated formulation technology to ensure the release of the drug nanocrystals as fine suspension when incorporated in a tablet in such a relatively high concentration (single dose: $250 \mathrm{mg}$ ). It must be noted that the tablet size (weight) has to be acceptable for the patient and that a dosing with two tablets should be avoided for reasons of patient compliance and marketing.

\section{Conclusions}

As the examples have shown, nanocrystal technology offers great benefits with only a few minor drawbacks (Table 4). It is clearly ideally suited for drugs with solubility problems. Particle size diminution and the resulting increase in particle surface, curvature, saturation solubility, and consequently the increased dissolution velocity, are important factors.

Solubility enhancement alone is not the only important factor. It becomes even more important when a drug has a narrow therapeutic window where it can be absorbed. In these cases the increased solubility and dissolution velocity lead to an acceptable bioavailability.

In addition, the nanocrystal technology enables formulations to be developed without the need of problematic surfactants (eg, Cremophor EL) which may cause enhanced side effects or adverse reactions. Furthermore, nanocrystals allow for a fast action onset, as the drug is absorbed quickly due to the fast dissolution of the nanoparticles. This is an advantage, especially for drugs which need to work fast (eg, naproxen for headache relief).

As discussed the enhanced solubility also leads to an identical or very similar absorption in fed and fasted conditions. Drugs which normally require food to become soluble will be bioequivalent as nanocrystals in fed and fasted states.

If it is necessary to give a large dosage in order to achieve reasonable blood levels for poorly soluble drugs resulting in increased side effects, the nanocrystal technology allows for smaller doses and thus decreased side effects.

Disadvantages are the sometimes long production times, eg, in pearl milling. However, new patents to accelerate large scale production have just been filed, eg, H42 (Müller and Moeschwitzer 2005). In addition, improved technologies are required to be able to produce tablets with high drug nanocrystal loads to formulate high dose drugs in - preferentially - one single tablet.

In future, more drugs will be poorly soluble and thus require smart formulation technologies to make them soluble and bioavailable. An increased awareness in patients not willing to suffer from unnecessary side effects will lead to an increased number of products using nanocrystals to reduce these risks. By modifying the nanocrystal surface it is possible to achieve a prolonged or a targeted release. This will be an important part of the work for the nanoparticles in future.

\section{References}

Anger S. 2005. PhD Thesis. Pharmazeutische Technologie. Berlin, Freie Universität.

Bhol KC, Alroy J, Schechter PJ. 2004. Anti-inflammatory effect of topical nanocrystalline silver cream on allergic contact dermatitis in a guinea pig model. Clin Exp Dermatol, 29:282-7.

Bhol KC, Schechter PJ. 2004. Suppressive effects of topical nanocrystalline silver on allergic contact dermatitis in mice. [abstract] Clin Invest Med, 274:196.

Bhol KC, Schechter PJ. 2005a. Topical nanocrystalline silver cream inhibits expression of matrix metalloproteinase-9 in animal models of allergic contact dermatitis. [abstract] J Invest Dermatol, 1244:117.

Bhol KC, Schechter PJ. 2005b. Topical nanocrystalline silver cream suppresses inflammatory cytokines and induces apoptosis of inflammatory cells in a murine model of allergic contact dermatitis. Brit J Dermatol, 152:1235-42.

Bruno JA, Doty BD, Gustow E, et al. 1992. Method of grinding pharmaceutical substances. US Patent 5518187. USA.

Bruno RP, Mcllwrick R. 1999. Microfluidizer processor technology for high performance particle size reduction, mixing and dispersion. Eur J Pharm Biopharm, 56:29-36.

Bushrab NF, Müller RH. 2003. Nanocrystals of poorly soluble drugs for oral administration. J New Drugs, 5:20-2.

Bushrab, N., F. 2005. PhD Thesis (in preparation). Pharmazeutische Technologie. Berlin, Freie Universität.

Chong-Hui G, Grant DJW. 2001. Estimating the relative stability of polymorphs and hydrates from heats of solution and solubility data. J Pharmacol Sci, 909:1277-87.

Cinzia De Vita VC. 2004. Nanostructured hybrid materials from aqueous polymer dispersions. Adv Colloid Interface Sci, 108-109C:167-85. 
Femia R. 2005. Megestrol acetate nanocrystal: Results of dose-escalating studies under fed and fasting conditions. amfAR's 17th National HIV/ AIDS Update Conference. California, USA.

Gassmann P, List M, Schweitzer A, et al. 1994. Hydrosols - alternatives for the parenteral application of poorly water soluble drugs. Eur J Pharm Biopharm, 40:64-72.

Grau MJ. 2000. Untersuchungen zur Lösungsgeschwindigkeit, Sättigungslöslichkeit und Stabilität von hochdispersen Arzneistoffsuspensionen. Dissertation. Pharmazeutische Technologie. Berlin, Freie Universität.

Hancock BC, Parks M. 2000. What is the true solubility advantage for amorphous pharmaceuticals? Pharmacol Res, 174:397-404.

Investigators, Diabetes Artherosclerosis Intervention Study. 2001. Effect of fenofibrate on progression of coronary - artery disease in type 2 diabetes: the Diabetes Atherosclerosis Intervention Study. Lancet 357:905-10.

Junghanns J - UAH. 2006. PhD Thesis (in preparation). Pharmazeutische Technologie. Berlin, Freie Universität.

Kanellos M. 2005. Moore says nanoelectronics face tough challenges. CNet News [online]. 9 March. URL: http://www.news.com/Mooresays-nanoelectronics-face-tough-challenges/2100-1006_3-5607422. html?tag=st.nl

Kazimierski P. 2005. Nanotechnology for medicine. Alexander von Humboldt Foundation Conference 2005, Piotr: Alexander von Humboldt Foundation.

Keck CM, Bushrab NF, Müller RH. 2004. Nanopure ${ }^{\circledR}$ nanocrystals for oral delivery of poorly soluble drugs. Particles, April 20-23, 2002. Orlando, Florida, USA.

Kipp JE, Wong JCT, Doty MJ, et al. 2003. Microprecipitation method for preparing submicron suspensions. US Patent 6607784. USA.

Kreuter J, Alyautdin RN, Kharkevich DA, et al. 1995. Passage of peptides through the blood - brain barrier with colloidal polymer particles nanoparticles. Brain Res, 6741:171-4.

Lee S, Nam K, Kim MS, et al. 2005. Preparation and characterization of solid dispersions of itraconazole by using aerosol solvent extraction system for improvement in drug solubility and bioavailability. Arch Pharm Res, 287:866-74.

List MA, Sucker H. 1988. Pat No. GB 2200048. Great Britian.

Liversidge GG, Conzentino P. 1995. Drug particle size reduction for decreasing gastric irritancy and enhancing absorption of naproxen in rats. Int J Pharm, 125:309-13.

Lyczak JB, Schechter PJ. 2005. Nanocrystalline silver inhibits antibiotic-, antiseptic-resistant bacteria. Clin Pharmacol Ther, 77:60.

Merisko-Liversidge E, Liversidge GG, Copper ER. 2003. Nanosizing: a formulation approach for poorly-water-soluble compounds. Eur $J$ Pharma Sci, 18:113-20.

Merisko-Liversidge E. 2002. Nanocrystals: resolving pharmaceutical formulation issues associated with poorly water-soluble compounds. Particles, April 20-23, 2002. Orlando, Florida, USA.

Merkle RC. 1999. Biotechnology as a route to nanotechnology. Trends Biotechnol,17:271-4.

Möschwitzer J, Müller RH. 2005. Method for the production of ultrafine submicron nanosuspensions. DE 102005011 786.4. Application, Germany.

Möschwitzer J. 2005. PhD Thesis (in preparation). Pharmazeutische Technologie. Freie Universität Berlin.

Möschwitzer J, Müller RH. 2004a. From the drug nanocrystal to the final mucoadhesive oral dosage form. International Meeting on Pharmaceutics, Biopharmaceutics and Pharmaceutical Technology, Nürnberg, Germany.

Möschwitzer J, Müller RH. 2004b. Nanosuspensions as formulation principle for chemical stabilization of chemically labile drugs. International Meeting on Pharmaceutics, Biopharmaceutics and Pharmaceutical Technology, Nürnberg, Germany.

Müller RH, Becker R, Kruss B, et al. 1999. Pharmaceutical nanosuspensions for medicament administration as systems with increased saturation solubility and rate of solution. US Patent 5858410 . USA.

Muller RH, Jacobs C, Kayser O. 2001. Nanosuspensions as particulate drug formulations in therapy: Rationale for development and what we can expect for the future. Adv Drug Deliv Rev, 471:3-19.
Müller RH, Jacobs C, Kayser O. 2003. DissoCubes - a novel formulation for poorly soluble and poorly bioavailable drugs. In Rathbone MJ, Hadgraft J, Roberts MS (eds). Modified-release drug delivery systems. New York: Marcel Dekker, pp. 135-49.

Müller RH, Lück M, Kreuter J. 1998. Arzneistofträgerpartikel für die gewebsspezifische Arzneistoffapplikation. PCT/EP98/06429. Germany.

Müller RH, Möschwitzer, JP. 2005. Method and apparatus for the production of ultrafine particles and coating of such particles. DE 102005053 862.2 Application, Germany.

Müller RH, Pardeike J, Hommoss A. 2006. Nanoparticles in therapeutics: drug nanocrystals and lipid nanoparticles. MSTI-Congress NanoTrends 2006. Berlin, Germany.

Müller RH, Peters K, Becker R, et al. 1995. Nanosuspensions - a novel formulation for the IV administration of poorly soluble drugs. 1st World Meeting of the International Meeting on Pharmaceutics, Biopharmaceutics and Pharmaceutical Technology, Budapest.

Müller RH. 2002. Nanopure technology for the production of drug nanocrystals and polymeric particles. 4th World Meeting of the Italian Association of Professors and Academic Researchers of Pharmaceutics, Pharmaceutical Technology, Biopharmaceutics and Regulatory Affairs. Florence, Italy.

Müller BW, Bleich J. 1996. Production of drug loaded microparticles by the use of supercritical gases with the Aerosol Solvent Extraction System (ASES) process. $J$ Microencapsulation, 132:131-9.

NanoCrystal ${ }^{\mathbb{}}$-Technology-Group 2005. Meeting the challenges of drug delivery. [Brochure] Elan Drug Delivery, Inc.

Noyes A, Whitney W. 1897. The rate of solution of solid substances in their own solutions. J Am Chem Soc, 19:930-4.

Pahl MH. 1991. Zerkleinerungstechnik. Cologne: TÜV Rheinland GmbH.

Megace ES ${ }^{\circledR}$ PI. 2005. Megace ES tablets [prescribing information]. Par Pharmaceutical Companies, Inc.

Sehgal SN. 1998. Rapamune RAPA, rapamycin, sirolimus: mechanism of action immunosuppressive effect results from blockade of signal transduction and inhibition of cell cycle progression. Clin. Biochem. 531: 335-340.

Shackleford DM, Faassen WA, Houwing N, et al. 2003. Contribution of lymphatically transported testosterone undecanoate to the systemic exposure of testosterone after oral administration of two andriol formulations in conscious lymph duct-cannulated dogs. J Pharmacol Exp Ther, 3063:925-33.

Shimizu S. 2003. Aprepitant Emend ${ }^{\circledR}$. New Drug Bulletins: The University of Utah Drug Information Service.

Speiser PP. 1998. Poorly soluble drugs: a challenge in drug delivery. In Müller RH, Benita S, Böhm B (eds). Emulsions and nanosuspensions for the formulation of poorly soluble drugs. Medpharm Stuttgart: Scientific Publishers, pp. 15-28.

Tunick MH, Van Hecken DL, Cooke PH, et al. 2002. Transmission electron microscopy of mozzarella cheeses made from microfluidized milk. J Agric Food Chem, 50:99-103.

Velikov K. 2006. Colloidal delivery systems for functional food design. 9th Annual NSTI Nanotechnology Conference and Trade Show, Nanotech 2006. Boston, Massachusetts, USA.

Willems L, van der Geest R, de Beule K. 2001. Itraconazole oral solution and intravenous formulations: a review of pharmacokinetics and pharmacodynamics. J Clin Pharm Ther, 26:159-61.

Witztum JL. 1996. Drugs used in the treatment of hyperdyslipidemias. In Hardman JG, Limbird LE, Monlinoff PB, et al. (eds). The Pharmacological Basis of Therapeutics. New York: McGraw-Hill, pp. 875-97.

Wua YL, Landisb A, Hettricka E, et al. 2004. The role of biopharmaceutics in the development of a clinical nanoparticle formulation of MK-0869: A beagle dog model predicts improved bioavailability and diminished food effect on absorption in human. Int J Pharm, 285:135-46. 
